\title{
How to Reconstruct an Open Abdominal Wall After Necrotizing Fasciitis?: Surgical Management in Difficult Cases
}

\author{
Seda ŞAHIN AKER ${ }^{\mathrm{a}}$, Arda ÖZDEMIR ${ }^{\mathrm{b}}, \quad$ Frrat ORTAÇa \\ aDepartment of Gynecology and Obstetrics, Ankara University Faculty of Medicine, Ankara, TURKEY \\ ${ }^{b}$ Department of Plastic and Reconstructive Surgery, Ankara University Faculty of Medicine, Ankara, TURKEY \\ This study was presented as a orally at the $17^{\text {th }}$ National TJOD Congress (April 24 $4^{\text {th }}$-April $28^{\text {th }} 2019$, Antalya, Turkey).
}

\begin{abstract}
Necrotizing fasciitis (NF) is a very fatal infection which is also known as flesh eating disease. Due to the rapid progression, early diagnosis, the use of broad spectrum antibiotics and aggressive surgical treatment are very essential to reduce morbidity and mortality. In some conditions, abdominal wall integrity cannot be maintained. Negative pressure wound therapy (NPWT) can be used for the management of acute and chronic wounds. Studies showed that negative pressure wound therapy combined with a split thickness skin graft (STSG) can help to heal wounds at NF. In this case, the patient suffered from type 1 NF caused by Pseudomonas aeruginosa, Klebsiella pneumoniae. We would like to demonstrate how to reconstruct an open abdominal wall after an endometrial carsinoma surgery with NPWT and STSG.
\end{abstract}

Keywords: Endometrial carsinoma; necrotizing fasciitis; split thickness skin graft; NPWT

Necrotizing fasciitis (NF) is a fatal infection causing necrosis of the soft tissue and fascia. The incidence of NF is $0.4 / 100,000 .{ }^{1} \mathrm{NF}$ has a high mortality rate so it is needed an early diagnosis and proper treatment. NF has multiple names such as gangrenous erysipelas, progressive bacterial synergistic gangrene, non-clostridial gas gangrene, hemolytic streptococcal gangrene, non-clostridia crepitate cellulites, bacterial synergistic gangrene, necrotizing cellulites, and phagedena gangrenosum. Wilson was the one who first described it in $1952 .{ }^{2} \mathrm{NF}$ has two types: Type $1 \mathrm{NF}$ is the most frequent form and caused by aerobic and anaerobic microorganism. Type $2 \mathrm{NF}$ is caused by monoclonal microorganism beta hemoliytic streptococcus or Group A streptococcus. There are several risk factors for NF. These are diabetes mellitus, surgery, malignancy, obesity, trauma, old age, chronic skin infection, and immune system deficiency. NF presents as painful, discoloration of the skin and a black necrotic tissue at the wound area. Ischemia and tissue necrosis can develop and local anaesthesia can occur because of the nerve damage. ${ }^{3}$ Generally immediate surgical debridement would be necessary due to the high mortality rate. In some conditions, abdominal wall integrity cannot be ensured. Negative pressure wound therapy (NPWT) can be used for the management of wounds. NPWT can be combined with split thickness skin graft (STSG) for reconstruction. ${ }^{4}$ In this case, the patient suffered from type 1 NF caused by Pseudomonas aeruginosa, Klebsiella pneumoniae. We would like to demonstrate how to reconstruct an open abdominal wall after an endometrial carsinoma surgery with NPWT and STSG.

Correspondence: Seda ŞAHIN AKER

Department of Gynecology and Obstetrics, Ankara University Faculty of Medicine, Ankara, TURKEY

E-mail: drsedasahinaker@hotmail.com

Peer review under responsibility of Journal of Clinical Obstetrics \& Gynecology. 


\section{CASE REPORT}

A 59-year-old Turkish woman was admitted to hospital with a complaint of a postmenopausal bleeding. After evaluation by a transvaginal sonogram which showed an endometrial thickness $(13 \mathrm{~mm})$, the and patient underwent a probe curettage. The pathology report showed a grade 1 endometrioid type of endometrial carcinoma. The patient had bleeding symptoms after curettage and a total abdominal hysterectomy and bilateral salpyngoophorectomy were performed. Final pathology report revealed that stage 1 A endometrioid type of endometrium carsinoma. Third day after surgery, the patient had fever $38^{\circ} \mathrm{C}$, tachycardia (102 beat $\left./ \mathrm{min}\right)$, swelling was spread to the upper abdominal wall with skin color changes, skin cellulitis and vaginal discharge. Computer tomography showed a vaginal cuff abscess and a suspicion of fecal contamination. Laboratory findings showed leukocyte count of $17.3 \times 10^{\wedge} 9 / \mathrm{L}$, hemogram count of $9,9 \mathrm{~g} / \mathrm{dL}$, procalcitonin count of $4,5 \mathrm{ng} / \mathrm{mL}$, albumin count of $24,3 \mathrm{~g} / \mathrm{dL}$, C-reactive protein (CRP) count of $173 \mathrm{mg} / \mathrm{L}$, sodium count of $136 \mathrm{mEq} / \mathrm{L}$, serum creatinine level of $0.6 \mathrm{mg} / \mathrm{dL}$, serum glucose $190 \mathrm{mg} / \mathrm{dL}$, and a sedimentation rate count of $92 \mathrm{~mm} / \mathrm{h}$. The patient had history of diabetes, hypertension and cardiac insufficiency. She used insulin, beta blockers and warfarin sodium. Because of the patient's status, she needed a surgical debridement. In surgery rectosigmoid junction showed a suspicious 2-3 cm diameter defect area. The patient was hemodynamically unstable so we didn't prefer any anastomosis or repairment. She underwent a Hartmann's procedure, abscess debridman and end-sigmoid colostomy procedure. Abdominal skin closed with a second look operation after 48 hours. After 48, skin cellulitis was expanded. Acute phase reactants increased, the figures were leukocyte count of $20,5 \times 10^{\wedge} 9 / \mathrm{L}$, procalcitonin count of $12,4 \mathrm{ng} / \mathrm{mL}, \mathrm{CRP}$ count of $278 \mathrm{mg} / \mathrm{L}$, and a sedimentation rate count of $99 \mathrm{~mm} / \mathrm{h}$. The patient then underwent wide surgical debridement and a vacuum sealing drainage dressing was placed to the open abdominal wall and a negative sucker was placed. The dressing was changed every 3 days. Postoperative histology showed chronic suppurative inflammation. Antibiotic therapy was given based on the culture results. Culture results showed Klebsiella pneumoniae and Pseudomonas aeruginosa. NPWT was applied until complete granulation coverage of all underlying anatomical structures was achieved. After 21 days of a negative pressure wound treatment, the abdominal wall defect was $15 * 15 \mathrm{~cm}$ diameter and the wound was with a granulation tissue. The patient underwent a split thickness skin graft operation. In this video article, we want to demonstrate how to reconstruct an open abdominal wall defect with a full thickness skin graft. After removing the granulation tissue, a good vascular supported tissue was seen and the necrotic wound was removed by a curette. The split thickness skin graft was taken from left leg's superolateral healty skin with a measure of $10 * 25 \mathrm{~cm}$ diameter and $3 \mathrm{~mm}$ thickness. The skin is meshed to cover the large wound area. The graft covered the whole open abdominal wall and stitched up with 4,0 polipropilen sutures. After 72 hours, coverage was opened and the graft was supported by a dressing chlorhexidine paraffin gauze BP Bactrigras ${ }^{\circledR}$ (Smith $\&$ Nephew, Ontario, Kanada) (Figure 1) and postoperatively, after one month the entire wound healed and the grafted skin survived (Figure 2). The patient was discharged and used a hernia belt to support for six months. After third month visit, cosmetic appearance and the integrity of the abdominal wall was very good (Figure 3) but at the sixth month visit, $3 * 3 \mathrm{~cm}$ of abdominal wall hernia occured (Figure 4 ) and continued to support with hernia belt. In order to use the photographs and videos a written consent had been obtained from the patient.

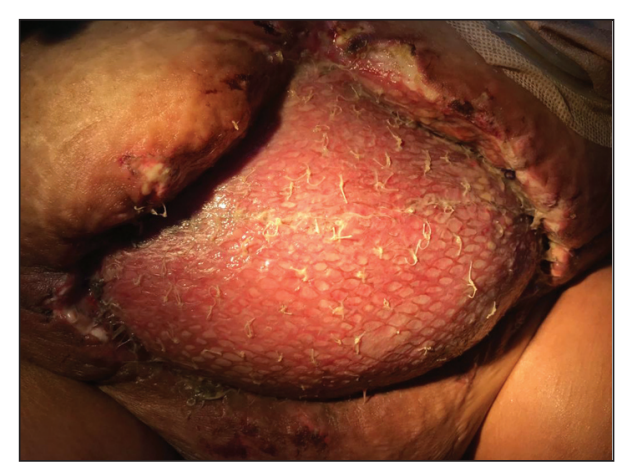

FIGURE 1: Seventy-two hours after split thickness skin graft surgery. 


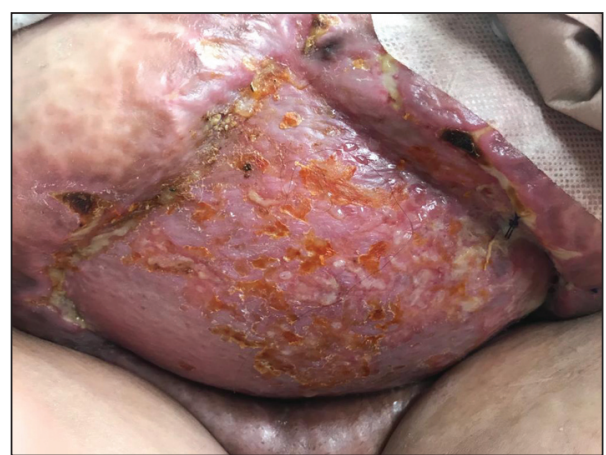

FIGURE 2: One month after split thickness skin graft surgery.

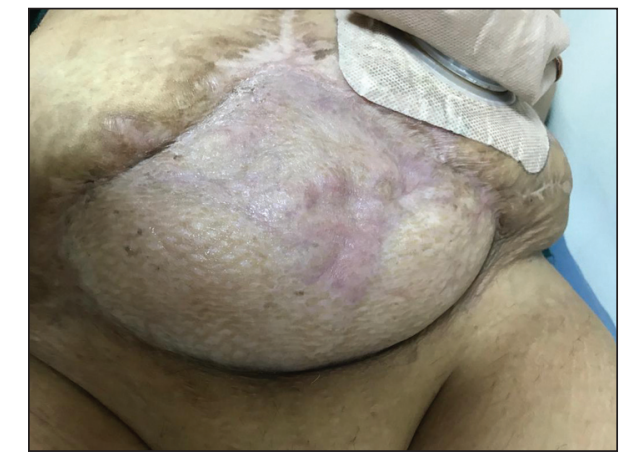

FIGURE 3: Three months month after split thickness skin graft surgery.

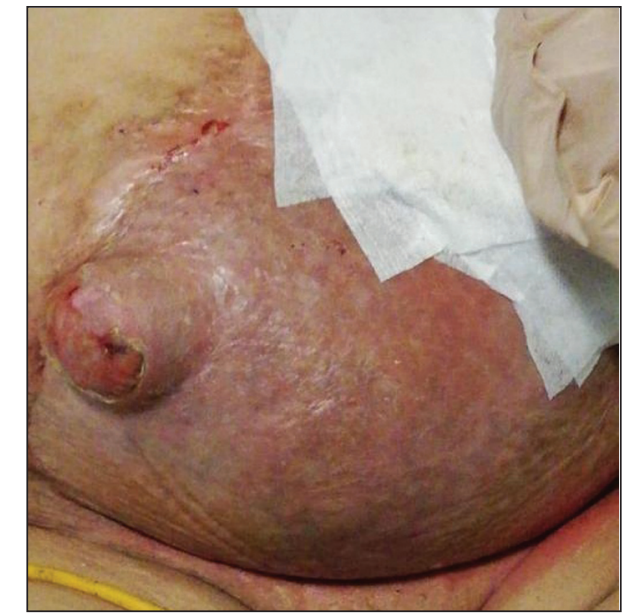

FIGURE 4: Six months month after split thickness skin graft surgery.

\section{DISCUSSION}

$\mathrm{NF}$, is a rare but very fatal infection which is also known as flesh eating disease. Due to the rapid progression, early diagnosis, the use of broad spectrum antibiotics and aggressive surgical treatment are very essential to reduce morbidity and mortality. Microbiologically, NF has been classified as polymicrobialtype 1 or monomicrobial-type 2. Polymicrobial infections are more common and caused by aerobic and anaerobic organisms just like in this case. Infection starts in the deep tissue plans. The clinical disease is expressed when organisms spread through the tissue along the deep fascia. The spread of bacteria results in thrombosis of blood vessels in dermal papilla, resulting in ischemia and gangrene of subcutaneous fat and dermis. ${ }^{5}$ Risk factors of NF are diabetes mellitus, malignancies, chronic disease, advanced age, alcohol abuse, intravenous drug use, renal failure, peripheral vascular disease, obesity, surgery, invasive procedures and penetrating injuries. Our patient had multiple risk factors; an endometrial carsinoma surgery history, diabetes mellitus, cardiac insufficiency and obesity (body mass index $=34.5$ $\mathrm{kg} / \mathrm{m}^{2}$ ). The patient got symptomatic within 72 hours with fever $\left(38^{\circ} \mathrm{C}\right)$, swelling of the upper abdominal wall, skin cellulitis, tachycardia, tachypnea and vaginal discharge. Normally the pain of NF is very severe but patients with diabetic neuropathy with loss of sensation, just like our patient, can experience minimal pain. Some clinical scores such as the laboratory risk indicator for NF (LRINEC) score can be used to diagnosis and differentiation of NF. The score of $\geq 8$ shows high risk, score 6-7 shows intermediate risk and below 5 shows low risk. ${ }^{6,7}$ The score of our case was 8 . Surgical debridement in a short period time lowers the mortality rate for NF with almost $50 \%$ so it is the cornerstone of the treatment. ${ }^{8}$ We decided immediate surgical debridement. It is very difficult to maintain abdominal wall integrity. NPWT can be used for the management of wounds. Negative pressure wound therapy was first described by Fleischmann et al., in 1993. ${ }^{9}$ Studies showed that negative pressure wound therapy combined with a split thickness skin graft can help to heal wounds with NF. ${ }^{4}$ NPWT has an effect on granulation tissue formation, reducing the wound volume and preparing wound for STSG. The negative pressure was directed at the surface of the wound through an interface between the wound and a polyurethane sponge and can be used at a constant or intermittent mode. Studies showed that 
NPWT can secure STSG and improve graft survival. ${ }^{10}$ We used NPWT before STSG to help healing the wound. NPWT prepares the wound bed and the negative pressure leads to an increased blood supply and migration of inflammatory cells into the wound region. Thus improves the graft acceptance. ${ }^{11}$ NPWT is a high priced product than other wound-care products, a cost-effectiveness analysis showed lower treatment expenses. ${ }^{12}$ Because NPWT is very effective to treat large, heavily exudating wounds and very successful at wound healing. So the adjusted cost per cubic centimeter volume reduction for the NPWT is lower than the other methods. Despite the colostomy, NPWT therapy was successfully applied. We decided to take a graft from left leg lateral side. The abdominal wall defect was $15^{*} 15 \mathrm{~cm}$ diameter and the STSG was taken from left leg's superolateral healty skin with a measure of $10 * 25 \mathrm{~cm}$ diameter and $3 \mathrm{~mm}$ thickness. After 30 days, graft acceptance was $100 \%$, wound healed and the patient was discharged (Figure 2). When STSGs applied to the open abdominal wall, the disadvantage of STSG is not providing a strong structural support and results in hernia. ${ }^{13}$ At the third month visit, cosmetic appearance and the integrity of the abdominal wall were very good (Figure 3 ) but at the sixth month visit, $3 * 3 \mathrm{~cm}$ of abdominal wall hernia occured (Figure 4) and continued to support with hernia belt.
In conclusion, $\mathrm{NF}$ is an uncommon condition and has serious morbidity-mortality rate. Surgical debridement is the cornerstone of the treatment. NGWT combined with a STSG can help to heal wounds with NF. Hence we made an open abdominal wall treatment with NGWT and STSG with an acceptable cosmetic appearance.

\section{Source of Finance \\ During this study, no financial or spiritual support was received neither from any pharmaceutical company that has a direct con- nection with the research subject, nor from a company that pro- vides or produces medical instruments and materials which may negatively affect the evaluation process of this study.}

\section{Conflict of Interest}

No conflicts of interest between the authors and / or family members of the scientific and medical committee members or members of the potential conflicts of interest, counseling, expertise, working conditions, share holding and similar situations in any firm.

\section{Authorship Contributions}

Idea/Concept: Seda Şahin Aker; Design: Seda Şahin Aker; Control/Supervision: Furat Ortaç; Data Collection and/or Processing: Seda Şahin Aker; Analysis and/or Interpretation: Seda Şahin Aker; Literature Review: Seda Şahin Aker; Writing the Article: Seda Şahin Aker; Critical Review: Furat Ortaç; References and Fundings: Seda Şahin Aker; Materials: Arda Özdemir, Seda Şahin Aker.

\section{REFERENCES}

1. File Jr TM, Tan JS, DiPersio JR. Group A streptococcal necrotizing fasciitis. Diagnosing and treating the "flesh-eating bacteria syndrome". Cleve Clin J Med. 1998;65(5): 241-9. [Crossref] [PubMed]

2. Carter PS, Banwell PE. Necrotising fasciitis: a new management algorithm based on clinical classification. Int Wound J. 2004;1(3): 189-98. [Crossref] [PubMed]

3. Kihiczak GG, Schwartz RA, Kapila R. Necrotizing fasciitis: a deadly infection. J Eur Acad Dermatol Venereol. 2006;20(4):365-9. [Crossref] [PubMed]

4. Gupta S. Optimal use of negative pressure wound therapy for skin grafts. Int Wound J. 2012;9 Suppl 1:40-7. [Crossref] [PubMed]
5. Puvanendran R, Huey JCM, Pasupathy S. Necrotizing fasciitis. Can Fam Physician. 2009;55(10):981-7. [PubMed]

6. El-Menyar A, Asim M, Mudali IN, Mekkodathil A, Latifi $\mathrm{R}, \mathrm{Al}$-Thani $\mathrm{H}$, et al. The laboratory risk indicator for necrotizing fasciitis (LRINEC) scoring: the diagnostic and potential prognostic role. Scand J Trauma Resusc Emerg Med. 2017;7;25(1):28. [Crossref] [PubMed] [PMC]

7. Wong $\mathrm{CH}$, Khin LW, Heng KS, Tan KC, Low CO. The LRINEC (Laboratory Risk Indicator for Necrotizing Fasciitis) score: a tool for distinguishing necrotizing fasciitis from other soft tissue infections. Crit Care Med. 2004; 32(7):1535-41. [Crossref] [PubMed]
8. Nawijn F, Smeeing DPJ, Houwert RM, Leenen $\mathrm{LPH}$, Hietbrink F. Time is of the essence when treating necrotizing soft tissue infections: a systematic review and meta-analysis. World J Emerg Surg. 2020;8;15:4. [PubMed]

9. Fleischmann W, Strecker W, Bombelli M, Kinzl L. [Vacuum sealing as treatment of soft tissue damage in open fractures]. Unfallchirurg. 1993;96(9):488-92. [PubMed]

10. Ye J, Xie T, Wu M, Ni P, Lu S. Negative pressure wound therapy applied before and after split-thickness skin graft helps healing of Fournier gangrene: a case report (CARECompliant). Medicine (Baltimore). 2015;94(5): e426. [Crossref] [PubMed] [PMC] 
11. Arslan E, Ozturk OG, Aksoy A, Polat G. Vacuum-assisted closure therapy leads to an increase in plasma fibronectin level. Int Wound J. 2011;8(3):224-8. [Crossref] [PubMed]

12. Vuerstaek JDD, Vainas T, Wuite J, Nele- mans P, Neumann MHA, Veraart JCJM, et al. State-of-the-art treatment of chronic leg ulcers: a randomized controlled trial comparing vacuum-assisted closure (V.A.C.) with modern wound dressings. J Vasc Surg. 2006;44(5): 1029-37. [Crossref] [PubMed]
13. Kovacević $P$, Velickov $A$, Stojiljković $D$, Velickov A, Ceranić Z. Reconstruction of full thickness abdominal wall defect following tumor resection: a case report. Srp Arh Celok Lek. 2014;142(5-6):347-50. [Crossref] [PubMed] 